\title{
New Semiempirical Equation Describing Evaporation and Condensation in Nonassociated Liquids
}

\author{
Mihail Yu. Gorbachev' ${ }^{1}$ and Anatholy S. Dimoglo ${ }^{2}$ \\ ${ }^{1}$ Institute of Chemistry, Academy of Sciences, Academic Street 3, 2028 Kishinev, Moldova \\ ${ }^{2}$ Gebze Institute of Technology, Istanbul Cd. 101, Cayirova, 41400 Kocaeli, Turkey \\ Correspondence should be addressed to Anatholy S. Dimoglo; dimoglo@gyte.edu.tr
}

Received 10 August 2013; Revised 28 November 2013; Accepted 1 December 2013

Academic Editor: Pedro M. Mancini

Copyright (c) 2013 M. Yu. Gorbachev and A. S. Dimoglo. This is an open access article distributed under the Creative Commons Attribution License, which permits unrestricted use, distribution, and reproduction in any medium, provided the original work is properly cited.

\begin{abstract}
The consideration of the evaporating and condensing molecules' interaction with the surface layer of nonassociated liquids made it possible to find an equation for relations between the saturated vapor pressure $P$, from one side, and surface tension, critical temperature, and molar volume of the liquids, from the other side. This equation takes into account the influence of intramolecular conformational transitions of evaporating molecules on the quantity of their energy barrier. There are two types of the condensation process for the nonassociated liquids: soft and hard molecular condensation. For some vapor molecules the surface layer of the liquids behaves as an impenetrable elastic film. In the case of evaporating molecules, their one-particle potential barrier caused by the surface molecules vibration is essentially higher for the conformationally flexible molecules than that for rigid ones.
\end{abstract}

\section{Introduction}

For nonassociated liquids in the state of phase equilibrium with their saturated vapor, both evaporation and condensation are responsible for the level of the vapor pressure. In its turn, the saturated vapor pressure of liquids $(P)$ is related also to the intensity of molecular motion (i.e., molecular kinetic temperature) therein. And really, any increase in absolute temperature $T$ of a liquid leads to the corresponding increase in the motion intensity, when the number of molecules evaporating per unit time from the unit surface (and, therefore, value of $P$ ) grows [1].

Usually the dependence of $P$ on $T$ can be described by means of the following equation (Antoine's equation [2]):

$$
\ln P=\frac{A-B}{(T+C)} .
$$

In (1) $A, B$, and $C$ are some constants which differ for various liquids. As a rule, for any liquid these constants are being defined on the basis of its experimental $P$ values. Other numerous correlations between $\ln P$ and $T$ are similar to (1), and they are formed by means of various additional addenda depending on $T$ to its right-hand side (see [3]). However, any above-mentioned correlation applied to the calculation of $P$ for a new liquid requires the definition of its own new constants depending on the nature of this new liquid.

Furthermore, it is well known that molecules of any liquid can be divided into two groups, according to the value of their one-particle kinetic energy [1]. The first group includes the so-called "hot" molecules. Their kinetic energy is greater than or equals to some critical for jumping value $E$. The molecules of the second group stay in their potential wells caused by the intermolecular attractive forces between these molecules. The given molecules take part in their vibration motion. The relative share $z$ of the molecules of the first group may be found by means of the Boltzmann statistics [1]:

$$
z=\exp \left(-\frac{E}{k T}\right),
$$

where $k$ is the Boltzmann constant and $E$ is the abovementioned critical value of one-particle energy. 
If we consider the investigated molecules as spherical particles, whose effective radius is proportional to $V^{1 / 3}(V$ is the molar volume of a liquid), then the following equation holds for the quantity $E[4,5]$ :

$$
E=f \sigma V^{2 / 3},
$$

where $\sigma$ denotes the surface tension of a liquid, and $f$ is a coefficient of proportionality, which is constant for many liquids (i.e., does not depend on $T$ ) $[4,5]$. Then the relative share $z$ of the above-mentioned jumping molecules (the first group) can be defined by means of the following equation:

$$
z=\exp \left(\frac{-g \sigma V^{2 / 3}}{T}\right)
$$

In $(4) g$ is a constant $(g=f / k)$ equal to $9.35 \times 10^{6}$ $\left(J^{-1} \mathrm{~K} \mathrm{~mol}^{2 / 3}\right)$ for various nonassociated liquids.

Some part of these jumping molecules can escape the investigated liquid phase and immediately form vapor phase [1]. It has also been shown [4] that the thermal kinetic energy of a nonassociated liquid (and, therefore, its value of $P$ ) increases with the increase of $z$ value. Bearing in mind all the above reasons, the aim of the present work is to find an equation that relates the quantity $P$ with the share $z$ of jumping molecules.

\section{Methods of Calculations}

2.1. Method of Calculations Evaporation in Nonassociated Liquid. In order to find the above equation, let us consider one mole of a liquid with conformationally rigid molecules. Hereinafter we suppose that the given liquid is in thermal equilibrium with its saturated vapor (its temperature $T$ is within the interval between its normal freezing and normal boiling points). We shall consider all the molecules of the investigated liquid as spherical particles (hard spheres) due to their fast mutual reorientations. The above value of $T$ is supposed to be high enough for the consideration to be valid.

Here it is to be noted that the share of the evaporating molecules of this liquid is less than that of the molecules jumping within its volume. It has been shown [6] that the surface layer of any nonassociated liquid is formed of its vibrating molecules.

Here, vibrating molecules are molecules of liquids with weight centres staying for a while in their potential wells formed by neighbouring molecules. Vibrating molecules may become jumping ones and vice versa, but they have also a period of "settled life," which allows for considering them as vibrating molecules.

Thus, molecules abandoning the liquid phase must have high enough values of their one-particle kinetic energy in order to get over the potential barrier $L$ caused by the vibrating molecules belonging to the surface layer. As far as the energy well of a vibrating molecule is proportional to $\sigma V^{2 / 3}$ (see (3)), hereinafter we shall consider that the quantity $L$ may be described by means of the following equation:

$$
L=l \sigma V^{2 / 3} .
$$

Equation (5) is similar to (3); however, there is a principal difference between them. The coefficient $l$ in (5) may depend on $T$ and on the nature of the investigated liquid phase as well. In other words, the quantity $L$ is proportional to the energy of the one-particle potential well and also may depend on the structure of the surface layer, namely, its thickness which is being defined by the chemical nature of its vibrating molecules and the value of $T$ of the given liquid phase. If oneparticle kinetic energy of a jumping molecule is higher than the above mentioned its critical value $L$, the molecule will be capable of escaping liquid phase. The relative share $s$ of such molecules may be found by means of the Boltzmann statistics [1]:

$$
s=\exp \left(-\frac{L}{k T}\right)=\exp \left(\frac{-æ \sigma V^{2 / 3}}{T}\right),
$$

where $æ(æ=l / k)$, in its turn, depends on $T$ and the nature of the liquid phase.

For different non-associated liquids it was shown [6] that molecules in their near-surface layers form a peculiar quasi crystal phase. This phase is being formed for the account of jumping molecules quitting the near-surface layers when passing to the gas phase. By this, the temperature of these layers becomes lower than that in the whole volume of the liquid.

The molecules of near-surface layers participate mainly in vibrational but not in jumping motion. Only they are responsible, from one part, for the surface tension phenomena in such liquids, and from the other part, namely, they form a potential barrier for evaporating or condensing molecules. The order in the given quasi crystal phase grows while nearing the surface layer of the liquid. From the liquid part, this area is messy enough, and its border is diffusive. In this work we suppose that the volume concentration of molecules in this area is practically equal to their concentration in the whole volume.

Now, let the total number of all jumping molecules be equal to $z N_{a}$ ( $N_{a}$ is Avogadro's number) and let their volume concentration in the given liquid phase be $n=z N_{a} / V$. Then the number $C$ of collisions (per unit time) among the abovementioned jumping molecules with energies greater than or equal to $L$ and the vibrating ones situated on some unit area of the surface layer may be defined from the equation below [1]:

$$
\begin{aligned}
C & =n\left(\frac{k T}{2 \pi m}\right)^{1 / 2} \exp \left(\frac{-L}{k T}\right) \\
& =\left(\frac{z N_{a}}{V}\right)\left(\frac{k T}{2 \pi m}\right)^{1 / 2} \exp \left(\frac{-æ \sigma V^{2 / 3}}{T}\right),
\end{aligned}
$$

where $m$ is the molecular mass of one molecule and the quantity $z$ is being defined by means of (4). At the same time, $C$ will be also equal to the number of evaporating jumping molecules, which are capable of quitting the investigated liquid through its unit surface per unit time (because their energy is high enough for getting over the surface layer). 
2.2. Describing Condensation in Nonassociated Liquids. Now let us consider the inverse process of molecular condensation as passing from the saturated vapor phase into the considered liquid one. Hereinafter we shall suppose that the process can be divided into two simultaneous processes. The first one is the condensation of those vapor molecules, whose one-particle kinetic energy is less than or equal to the above-mentioned critical energy $E$ (see (3)). In this case, attractive forces between vapour molecules and vibrating surface molecules are capable of fixing the former ones on the surface of the liquid. The number $D$ of the vapor molecules that are being fixed on the area unit of this surface per unit time may be easily found by means of the following equation [1]:

$$
D=\gamma\left(\frac{k T}{2 \pi m}\right)^{1 / 2}\left[1-\exp \left(-\frac{E}{k T}\right)\right]=\gamma\left(\frac{k T}{2 \pi m}\right)^{1 / 2}(1-z),
$$

where $\gamma$ is the value of the total volume's concentration for the molecules of the liquid under study in its saturated vapor phase. As far as for the considered fixed vapor molecules the critical value of one-particle kinetic energy $E$ is being defined by (3); our (8) contains $z$ as its parameter (see (4)). However, it should be noted that in (8) $z$ denotes the relative share of those vapor molecules which can be fixed on the liquid surface due to the intermolecular attractive forces. The condensation of such "slow" molecules may be called as "soft" condensation.

The presence of quasi-crystal area consisting of a few surface layers of the liquid (see [6]) is the reason of the fact that molecules moving to the surface layer (from either gas phase or liquid phase) must necessarily be influenced by a potential that has been formed by the molecules of the quasi-crystal area. This potential (from both sides of the very surface layer) will look like a Morse curve. However, the Morse curve, be it nearby the layer or in departure of it, can be represented by two parabolas, one for the area of minimum and the other for the more distant area. Thus, the energy of the quitting the surface level molecules will be described by two squared members being kinetic and potential energies of their interaction with quasi crystal molecules. According to the introduced approximation, potential energy of a molecule will quadratically depend on its distance till the very surface layer.

In this way, square roots will appear nowhere (including the equation for the particles balance as well). It becomes clear that the minimum for the Morse potential related to the gas phase is vacant, and a vapor molecule with low energy can be settled there, finishing in this way the very surface layer. This minimum lies in a space inside the gas phase but not inside the layer mentioned. The surface layer lies in the area of potential energy of the intermolecular interaction maximum. However, a softly condensed molecule, when getting in the minimum, imbeds anyway into the surface layer, sooner or later, without getting additional energy.

As a result, quasi crystal phase presence and low kinetic energy of its vibrating molecules cause soft condensation instead of evaporation. The energy of the softly condensed molecules redistributes at once by vibrating molecules of the quasi crystal area, and it is much more harder for them to quit the surface of the liquid; it is easier and more favorably to embed into it.

The second above-mentioned condensation process is the condensation of those vapor molecules, whose one-particle kinetic energy is greater than or equal to the value of $L$ (see (5)). This energy is high enough for getting over the potential barrier formed by the molecules vibrating on the surface of the liquid. The number $H$ of these "quick" vapor molecules penetrating into the volume of the liquid phase under study (per unit time and through a unit area of its surface) is defined by the equation below [1]:

$$
\begin{aligned}
H & =\gamma\left(\frac{k T}{2 \pi m}\right)^{1 / 2} \exp \left(-\frac{L}{k T}\right) \\
& =\gamma\left(\frac{k T}{2 \pi m}\right)^{1 / 2} \exp \left(\frac{-æ \sigma V^{2 / 3}}{T}\right),
\end{aligned}
$$

where $æ(æ=l / k)$ may depend on $T$ and on the nature of the investigated liquid phase (the coefficient $l$ is explained before, relative to (5)). The condensation of such "quick" molecules may be called as "hard" condensation.

Thus, just the vibrating molecules that form the surface layer of any liquid can cause the two above-considered condensation processes: (1) condensation of molecules, whose energy is less than or equal to $E$; (2) condensation of those molecules, whose energy is greater than or equal to $L$. For molecules with their one-particle kinetic energy ranging from $E$ up to $L$, the surface layer of the liquid phase is an elastic interfacial molecular film, which reflects the given molecules back into the saturated vapor phase.

For the saturated vapor phase, which is in equilibrium state with the corresponding liquid phase, the number $C$ must be equal to the sum of numbers $D$ and $H$. In this way, we have from (7)-(9) (after cancelling their common multiplier $\left.(k T / 2 \pi m)^{1 / 2}\right)$ the following equality:

$$
\left(\frac{z N_{a}}{V}\right) \exp \left(\frac{-æ \sigma V^{2 / 3}}{T}\right)=\gamma\left(1-z+\exp \left(\frac{-æ \sigma V^{2 / 3}}{T}\right)\right) .
$$

Next, if it has been supposed that the saturated vapor phase obeys the perfect gas law, then the concentration $\gamma$ can be expressed by means of the following equation:

$$
\gamma=\frac{P}{k T},
$$

where $P$ is the saturated vapor pressure [1]. From (10) and (11) one can easily obtain the following expression used to calculate values of $P$ :

$$
P=\left(\frac{z R}{V}\right) \exp \left(\frac{-æ \sigma V^{2 / 3}}{T}\right)\left[1-z+\exp \left(\frac{-æ \sigma V^{2 / 3}}{T}\right)\right]^{-1},
$$

where $R\left(R=k N_{a}\right)$ is the gas constant $(R=$ $8.3144 \mathrm{Jmol}^{-1} \mathrm{~K}^{-1}$ ), and $z$ is being defined by means of (4). 
TABLE 1: To the definition of the temperature dependence of $æ$.

\begin{tabular}{|c|c|c|c|c|c|c|c|c|c|}
\hline No. & Compound & $\begin{array}{l}\sigma \times 10^{3} \\
\left(\mathrm{~N} \mathrm{~m}^{-1}\right)\end{array}$ & $\begin{array}{c}V \times 10^{6} \\
\left(\mathrm{~m}^{3} \mathrm{~mol}^{-1}\right)\end{array}$ & $\begin{array}{c}T \\
(\mathrm{~K})\end{array}$ & $\begin{array}{c}T_{c} \\
(\mathrm{~K}) \\
\end{array}$ & $\begin{array}{c}P \\
(\mathrm{~Pa}) \\
\end{array}$ & $\tau$ & $\begin{array}{c}æ \times 10^{-7} \\
\left(J^{-1} \mathrm{~K} \mathrm{~mol}^{2 / 3}\right)\end{array}$ & $\begin{array}{c}\xi \times 10^{-7} \\
\left(\mathrm{~J}^{-1} \mathrm{Kmol}^{2 / 3}\right)\end{array}$ \\
\hline \multirow{2}{*}{1} & \multirow{2}{*}{ Fluorine } & 19.07 & 23.48 & 65.00 & \multirow{2}{*}{144.3} & 4719 & 0.4505 & 2.6407 & 5.8617 \\
\hline & & 13.42 & 25.17 & 85.20 & & 101325 & 0.5904 & 3.4600 & 5.8604 \\
\hline \multirow{2}{*}{2} & \multirow{2}{*}{ Silane } & 16.17 & 51.85 & 153.15 & \multirow{2}{*}{269.6} & 62104 & 0.5681 & 3.3305 & 5.8625 \\
\hline & & 15.11 & 52.77 & 161.30 & & 101325 & 0.5983 & 3.5082 & 5.8636 \\
\hline \multirow{2}{*}{3} & Carbon & 24.60 & 98.76 & 311.45 & \multirow{2}{*}{556.4} & 26795 & 0.5598 & 3.2795 & 5.8583 \\
\hline & tetrachloride & 20.42 & 103.91 & 349.95 & & 101325 & 0.6290 & 3.6904 & 5.8671 \\
\hline
\end{tabular}

TABLE 2: Towards the evaluation of the constant $\xi$.

\begin{tabular}{|c|c|c|c|c|c|c|c|}
\hline No. & Compound & $\begin{array}{l}\sigma \times 10^{3} \\
\left(\mathrm{~N} \mathrm{~m}^{-1}\right)\end{array}$ & $\begin{array}{c}V \times 10^{6} \\
\left(\mathrm{~m}^{3} \mathrm{~mol}^{-1}\right)\end{array}$ & $\begin{array}{c}T \\
(\mathrm{~K}) \\
\end{array}$ & $\begin{array}{l}T_{c} \\
(\mathrm{~K}) \\
\end{array}$ & $\begin{array}{c}P \\
(\mathrm{~Pa}) \\
\end{array}$ & $\xi$ \\
\hline 1 & Nitrogen & 8.88 & 34.73 & 77.35 & 126.2 & 101325 & 5.9176 \\
\hline 2 & Carbon monoxide & 9.58 & 34.88 & 81.00 & 132.9 & 93599 & 5.8474 \\
\hline 3 & Oxygen & 13.20 & 28.07 & 90.19 & 154.35 & 101325 & 5.8607 \\
\hline 4 & Methane & 15.36 & 36.17 & 100.00 & 190.85 & 34000 & 5.8752 \\
\hline 5 & Ethylene & 18.56 & 48.05 & 158.46 & 282.4 & 50446 & 5.8838 \\
\hline 6 & Trifluorochloromethane & 18.37 & 63.40 & 163.15 & 301.9 & 16140 & 5.9117 \\
\hline 7 & Perchloryl fluoride & 20.12 & 59.5 & 223.15 & 368.4 & 89346 & 5.8673 \\
\hline 8 & Iodomethane & 29.72 & 63.1 & 303.15 & 528 & 65143 & 5.8570 \\
\hline 9 & Carbon disulfide & 31.85 & 61.0 & 303.15 & 552 & 57943 & 5.9133 \\
\hline 10 & Arsenic tribromide & 29.10 & 109.1 & 494.0 & 785 & 101325 & 5.8899 \\
\hline
\end{tabular}

In order to use (12) in practice, we should define the dependence of the quantity $æ$ on $T$ and the nature of the investigated liquid phase.

\section{Results and Discussion}

3.1. Definition of the Temperature Dependence of $\alpha$. To define the dependence of $æ$ on $T$, let us consider the compounds presented in Table 1. (Here it should be reminded that we consider liquids, whose molecules are conformationally rigid.)

Experimental values of $\sigma, V$, and $P$ for all these compounds that participate in the calculation of $æ$ are taken from [3, 7-11]. The comparison of numerical values of $æ$ calculated with their use in (12) shows that for all compounds from Table $1 æ$ is directly proportional to $\tau$, where $\tau$ ( $\tau=$ $T / T_{c}$ ) denotes the reduced temperature of the compounds. Hereinafter $T_{c}$ denotes critical temperatures of investigated liquids. For the liquids presented in Table 1 their values of $T_{c}$ were taken from [7]. The data in the last column of Table 1 show that the ratio $\xi(\xi=æ / \tau)$ remains constant and does not depend on $T$ and the nature of the liquid under study. Thus, the expression for the quantity æentering (12) looks like

$$
æ=\frac{\xi T}{T_{c}} .
$$

Then (12) will have the form

$$
P=\left(\frac{z R T}{V}\right) \exp \left(\frac{-\xi \sigma V^{2 / 3}}{T_{c}}\right)\left[1-z+\exp \left(\frac{-\xi \sigma V^{2 / 3}}{T_{c}}\right)\right]^{-1}
$$

Here it is worth to be noted that the value of $z$ in (14) has been defined by means of (4) with the symbol $T$ (but not $T_{c}$ ) in the name of the exponent.

3.2. Towards the Evaluation of the Constant $\xi$. In order to verify (13) and (14) and to define the quantity $\xi$ more exactly, the compounds presented in Table 2 were investigated. Experimental values of $\sigma, V, T_{c}$, and $P$ were taken from $[3,7-$ 13].

The data in Table 2 show that $\xi$ does remain constant for these compounds, although their chemical structures differ significantly. The average numerical value of the constant $\xi$ defined from the data sets in Tables 1 and 2 is equal to $5.8748 \times$ $10^{7}\left(\mathrm{~J}^{-1} \mathrm{~K} \mathrm{~mol}^{-2 / 3}\right)$.

Now let us consider the case when our molecules have $N$ energetically degenerated (or quasi-degenerated) conformational states in the liquid phase. It has been shown [14] that the intramolecular conformational transitions occurring among these states will lead to the corresponding increase in the total number of bimolecular collisions between neighboring molecules. This increase can be described (see [14]) by means of the function $G(N)$, whose analytical form is

$$
G(N)=(1-\theta \ln N)^{-1} .
$$

In (15) its dimensionless constant $\theta$ does not depend on $T$ and the nature of the liquid phase. It is equal to 0.05681 [14]. (For liquids with conformationally rigid molecules $N=1$ and $G(1)=1$.)

Now let us consider the process of piercing of the evaporating conformationally flexible "hot" molecules through the vibrating molecules of the surface layer. Hereinafter we shall suppose that these vibrating molecules are fixed in one of 
Table 3: To the definition of the dependence of $\omega$ on $N$.

\begin{tabular}{lccccccccc}
\hline No. & Compound & $N$ & $\begin{array}{c}\sigma \times 10^{3} \\
\left(\mathrm{~N} \mathrm{~m}^{-1}\right)\end{array}$ & $\begin{array}{c}V \times 10^{6} \\
\left(\mathrm{~m}^{3} \mathrm{~mol}^{-1}\right)\end{array}$ & $\begin{array}{c}T \\
(\mathrm{~K})\end{array}$ & $\begin{array}{c}T_{c} \\
(\mathrm{~K})\end{array}$ & $\begin{array}{c}P \\
(\mathrm{~Pa})\end{array}$ & $\omega$ & $\omega /[G(N)]^{1 / 2}$ \\
\hline 1 & Ethane & 3 & 18.47 & 53.49 & 170.00 & 305.4 & 42940 & 6.1065 \\
2 & Trimethylamine & $2 \times 3^{3}$ & 16.24 & 88.11 & 273.15 & 433.2 & 90271 & 6.6650 & 5.86129 \\
3 & 1,4-Dioxane & 4 & 27.88 & 89.3 & 333.15 & 587 & 23803 & 6.1551 & 5.9078 \\
\hline
\end{tabular}

their conformational states, due to the action of the attractive force field existing between them and also due to the abovementioned absence of the translational jumping motion for the molecules of the surface layer [6]. In other words, it is presupposed that the presence of uncompensated attractive force (the latter causes the surface tension in the investigated liquid and is directed into its volume) leads to the fixation of each molecule of the surface layer in one of its conformations. Thus, the evaporating "hot" molecules, which are capable of making transitions among their conformational states, will pierce the surface layer formed by the vibrating molecules existing in only one conformational state.

3.3. Evaporating Conformationally Flexible Molecules. Further, let us consider interaction of two neighboring molecules of the liquid under study. If each of these molecules can have $N$ conformational states, then the increase in the number of their bimolecular collisions is being described by means of the function $G(N)$ (see (15)). Now let us imagine that for one of these molecules (hereinafter, the first molecule) its conformational transitions are stopped (i.e., the molecule is fixed in one of its conformations). In this case, the increase $\dot{I}$ in the number of bimolecular collisions between the considered molecules will be caused by conformational transitions of the second (conformationally flexible) molecule. As the situation under consideration is symmetrically reversible with respect to both molecules (namely, the first molecule is considered as conformationally flexible and the second one is conformationally rigid), so the above increase $\dot{I}$ is to be equal to the square root of the function $G(N)$ :

$$
\dot{I}=[G(N)]^{1 / 2} \text {. }
$$

And in the case, when both neighboring molecules interact while doing their conformational transitions, the total increase in the number of their bimolecular collisions will be equal to $\dot{I}^{2}$ (and, therefore, to $G(N)$ ).

When the evaporating molecules of the liquid phase pierce through the vibrating molecules of its surface layer, we have the realization of the above-considered situation in practice. Thinking the evaporating molecules as piercing the surface layer, we deal with the translational motion of a conformationally flexible molecule through the layer of conformationally rigid ones. Hereafter we shall consider that the one-particle potential barrier $L$ (see (5)) which must be got over by this molecule is also proportional to the number of its bimolecular collisions with the corresponding molecules of the surface layer. Thus, in order to calculate the barrier $L$ adequately, we must take into account the increase in the number of the bimolecular collisions which are caused by the conformational transitions of this evaporating molecule. Bearing in mind the above-mentioned reasons related to the quantity $\dot{I}$ describing this increase (see (16)), we can rewrite (5) in the following form:

$$
L=[G(N)]^{1 / 2} l \sigma V^{2 / 3} .
$$

Thus, for the saturated vapor pressure $P$ of those liquids, whose molecules can have their conformational transitions, the following final expression holds:

$$
\begin{aligned}
P= & \left(\frac{z R T}{V}\right) \exp \left(\frac{-\xi[G(N)]^{1 / 2} \sigma V^{2 / 3}}{T_{c}}\right) \\
& \times\left[1-z+\exp \left(\frac{-\xi[G(N)]^{1 / 2} \sigma V^{2 / 3}}{T_{c}}\right)\right]^{-1} .
\end{aligned}
$$

In order to verify (18) let us therein denote the product $\xi[G(N)]^{1 / 2}$ as $\omega$. The values of $\omega$ calculated on the basis of (18) are presented in Table 3 for the liquids, whose molecules have conformational transitions.

Experimental values of $\sigma, V, T_{c}$, and $P$ required for the calculation of $\omega$ were taken from $[3,7,8,10,15]$. Here the definition of $N$ (the number of one-particle conformational states for the molecules of the investigated liquids) is to be mentioned. For any such molecule, the value of $N$ in (15) and (18) is supposed to be equal to the total number of local minima on the surface of its full internal potential energy, which arise on this surface under all possible internal rotations and intramolecular inversions that change the conformation of its skeleton $[5,16]$. All its atoms are considered hereinafter as non-equivalent. Thus, in the case of ethane (see Table 3) its molecule may pass through three its possible (hindered) conformations, which arise from the internal rotations around $\mathrm{C}-\mathrm{C}$ bond.

In the case of trimethylamine, the internal rotation around each of its $\mathrm{C}-\mathrm{N}$ bonds can be characterized by the presence of three local minima on the surface of its internal one-particle potential energy [17]. As the one-particle number of the above $\mathrm{C}-\mathrm{N}$ bonds is equal to three, so the number of the minima connected with three internal $\mathrm{C}-\mathrm{N}$ rotations will be $3^{3}$. For the molecule of trimethylamine we have also to take into account the spatial inversion of its nitrogen atom [17]. The given type of internal one-particle motion leads to the total number of the above mentioned minima equal to $2 \times 3^{3}$.

1,4-Dioxane may have intra-molecular conformational transitions among four its possible conformations: two conformations of the type "chair" and two conformations of the type "bath" [17]. So, for 1,4-dioxane $N=4$. The usage of 
TABLE 4: The calculation of the quantity $P$ by means of (18).

\begin{tabular}{|c|c|c|c|c|c|c|c|c|}
\hline \multirow{2}{*}{ No. } & \multirow{2}{*}{ Compound } & \multirow{2}{*}{$N$} & \multirow{2}{*}{$\begin{array}{l}\sigma \times 10^{3} \\
\left(\mathrm{~N} \mathrm{~m}^{-1}\right)\end{array}$} & \multirow{2}{*}{$\begin{array}{l}V \times 10^{6} \\
\left(\mathrm{~m}^{3} \mathrm{~mol}^{-1}\right)\end{array}$} & \multirow{2}{*}{$\begin{array}{l}T \\
(\mathrm{~K})\end{array}$} & \multirow{2}{*}{$\begin{array}{l}T_{c} \\
(\mathrm{~K})\end{array}$} & \multicolumn{2}{|c|}{$P(\mathrm{~Pa})$} \\
\hline & & & & & & & Calc. & Exper. \\
\hline 1 & 2 & 3 & 4 & 5 & 6 & 7 & 8 & 9 \\
\hline 1 & Argon* & 1 & $\begin{array}{l}13.39 \\
12.62\end{array}$ & $\begin{array}{l}27.97 \\
28.49\end{array}$ & $\begin{array}{l}83.81 \\
87.29\end{array}$ & 150.8 & $\begin{array}{l}68053 \\
101231\end{array}$ & $\begin{array}{r}68750 \\
101325\end{array}$ \\
\hline 2 & Krypton & 1 & 16.40 & 34.17 & 115.76 & 209.4 & 72281 & 72920 \\
\hline 3 & Xenon & 1 & 19.30 & 43.34 & 161.36 & 289.7 & 82319 & 81627 \\
\hline 4 & Diborane & 1 & 16.49 & 61.92 & 163.15 & 290 & 34422 & 34062 \\
\hline 5 & Chlorine & 1 & 35.69 & 42.68 & 201.45 & 417.0 & 12845 & 13332 \\
\hline 6 & Difluorodichloromethane & 1 & 18.81 & 78.10 & 223.15 & 385.2 & 38763 & 39330 \\
\hline 7 & Bromine & 1 & 44.10 & 50.90 & 286.15 & 584 & 16887 & 16799 \\
\hline 8 & Titanium tetrabromide & 1 & 29.68 & 138.9 & 433.15 & 795.6 & 15814 & 15720 \\
\hline 9 & Mercury(II) bromide & 1 & 58.30 & 72.1 & 549.15 & 1011 & 36193 & 37732 \\
\hline 10 & Propane & $3^{2}$ & 19.20 & 71.83 & 203.15 & 369.8 & 23212 & 24312 \\
\hline 11 & Dimethyl sulfide & $3^{2}$ & 24.46 & 73.27 & 293.15 & 503.0 & 53910 & 53033 \\
\hline 12 & Bromoethane & 3 & 24.90 & 74.89 & 293.15 & 503.8 & 50635 & 51436 \\
\hline 13 & Cyclopentene & 2 & 22.65 & 88.23 & 293.15 & 506.0 & 42258 & 41621 \\
\hline 14 & 1,2-Dichloroethane & 3 & 25.40 & 83.7 & 343.15 & 561 & 63965 & 64631 \\
\hline 15 & Toluene & 6 & 22.90 & 112.8 & 343.15 & 591.7 & 28256 & 27164 \\
\hline 16 & o-Xylene & $6^{2}$ & 24.32 & 127.7 & 343.15 & 632.2 & 8301 & 8426 \\
\hline 17 & m-Xylene & $6^{2}$ & 23.16 & 129.1 & 343.15 & 619.2 & 10199 & 10121 \\
\hline 18 & p-Xylene & $6^{2}$ & 22.86 & 130.0 & 343.15 & 616.2 & 10533 & 10501 \\
\hline 19 & Ethylbenzene & $3 \times 6$ & 23.39 & 129.1 & 343.15 & 619.6 & 10970 & 11296 \\
\hline 20 & 1,2-Dichloropropane & $3^{2}$ & 21.50 & 105.1 & 353.15 & 577 & 59250 & 60704 \\
\hline 21 & Sulfur monochloride & 2 & 29.10 & 89.63 & 393.15 & 665 & 63171 & 62822 \\
\hline 22 & 1,3,5-Trimethyl-benzene & $6^{3}$ & 15.01 & 163.0 & 437.9 & 642.1 & 100882 & 101325 \\
\hline 23 & Naphthalene & 1 & 22.10 & 146.5 & 491.1 & 748.4 & 100010 & 101325 \\
\hline
\end{tabular}

${ }^{*}$ The quantity $P$ for argon was calculated at its triple point and at its normal boiling one.

the above considered values of $N$ for the calculation of the ratio $\omega /[G(N)]^{1 / 2}$ shows (see Table 3 ) that this ratio is the constant $\xi$ found above (cf. the data of Tables 2 and 3 ).

Thus, bearing in mind that $G(1)=1$, we can use (18) for the calculations of the quantity $P$ for various nonassociated liquids formed by both conformationally rigid and conformationally flexible molecules.

3.4. The Calculation of the Quantity Vapor Pressure of the Inorganic and Organic Liquids. The values of the saturated vapor pressure of the inorganic and organic liquids presented in Table 4 were calculated by means of (18). Experimental values of $\sigma, V, T_{c}$ needed for this calculation were taken from $[1,3,7-11,15]$ and also from [18-27]. The values of $N$ were calculated on the base of data presented in $[17,28]$. Note that in the case of the benzene derivatives (see Table 4) the internal rotation around any of their $\mathrm{C}-\mathrm{C}$ bonds (where one of carbon atoms belongs to the benzene ring) corresponds to six local minima of their one-particle potential energy [17].

Thus, for instance, the total number $N$ of 1,3,5-trimethylbenzene will be $6^{3}$. The comparison of the calculated values of $P$ and the experimental ones taken from $[3,8,9,15$, 21,23 ] shows that (18) describes the quantity $P$ adequately.
The average absolute value (module) of calculation error for $P$ is $1.6 \%$ (Table 4 ).

However, such low-boiling quantum liquids as helium and hydrogen do not obey (18). This equation does not feet also for liquid metals, ionic liquids, and the chemical compounds, whose molecules are strongly associated in their liquid phase: water, alcohols, and so on. Thus, for instance, for quinoline being the associated liquid (and considered at its normal boiling point- $510.85 \mathrm{~K}[15]$ ), experimental values of $\sigma, V$, and $T_{c}$ are equal to $23.23 \times 10^{-3}\left(\mathrm{Nm}^{-1}\right), 142.0 \times 10^{-6}$ $\left(\mathrm{m}^{3} \mathrm{~mol}^{-1}\right)$, and $782.2 \mathrm{~K}$, respectively $[15,29,30]$. The value of $P$ calculated by means of (18) equals $117305 \mathrm{~Pa}$ (instead of $101325 \mathrm{~Pa}$ ). At the same time, naphthalene, whose molecules are nonpolar, obeys (18) at its normal boiling point (see Table 4).

\section{Conclusion}

The following conclusions may be drawn. Equation (18) allows us to perform the calculation of the saturated vapor pressure for various nonassociated liquids. There are two types of the condensation process of the nonassociated liquids: soft and hard molecular condensation. For a part of 
vapor molecules their surface layer behaves as some impenetrable elastic film. For the evaporating conformationally flexible molecules their one-particle potential barrier caused by the vibrating surface molecules is essentially higher than that for the evaporating conformationally rigid ones. The increase in the value of this barrier can be properly described by means of (17).

\section{Conflict of Interests}

The authors declare that there are no competing financial interests related to the publication of this paper.

\section{References}

[1] E. A. Moelwyn-Hughes, Physical Chemistry, Pergamon Press, London, UK, 1961.

[2] C. Antoine, "Tension des vapors: nouvelle relation entre les tension et les temperatures," Comptes Rendus, vol. 107, pp. 681$684,1888$.

[3] R. C. Reid, J. M. Prausnitz, and T. K. Sherwood, The Properties of Gases and Liquids, McGraw-Hill, New York, NY, USA, 1977.

[4] M. Y. Gorbachev, "Thermal kinetic energy of liquids with conformationally rigid molecules," Physics and Chemistry of Liquids, vol. 44, no. 2, pp. 145-152, 2006.

[5] M. Y. Gorbachev, "Influence of excited molecules on the process of frictional flow of nonassociated liquids," Physics and Chemistry of Liquids, vol. 42, no. 3, pp. 269-278, 2004.

[6] M. Y. Gorbachev, "Dependence of surface tension of nearboiling non-associated liquids on their molar volume and some critical constants," Physics and Chemistry of Liquids, vol. 39, no. 3, pp. 315-325, 2001.

[7] J. A. Dean, Ed., Handbook of Organic Chemistry, McGraw-Hill, New York, NY, USA, 1987.

[8] N. B. Vargaftik, Tables of Thermophysical Properties of Liquids and Gases, Halsted Press, New York, NY, USA, 1975.

[9] A. G. Morachevsk and I. B. Sladkov, Phisiko-Khimicheskie Svoistva Molekuljarnykh Neorganicheskikh Soedinenii, Khimia, Sankt Peterburg, Russia, 1996.

[10] B. P. Nikolsky, Ed., Spravochnik Khimika. Tom 1, Khimia, Moscow, Russia, 1963.

[11] G. G. Devjatykh and A. D. Zorin, Letuchie Neorganicheskie Gidridy Osoboi Chistoty, Nauka, Moscow, Russia, 1974.

[12] S. D. Razumovskii, Kislorod-Elementarnye Formy i Svoistva, Khimia, Moscow, Russia, 1979.

[13] A. A. Ravdel and A. M. Ponomareva, Eds., Kratky Spravochnik Phisikohimicheskikh Velichin, Khimia, Leningrad, Russia, 1983.

[14] M. Y. Gorbachev, "Influence of transitions among degenerated states of atoms and molecules on some physico-chemical quantities of liquids: Vaporization entropies of liquid 3d-metals," Physics and Chemistry of Liquids, vol. 38, no. 1, pp. 17-23, 2000.

[15] V. A. Rabinovich and Z. Ja. Khavin, Kratky Khimichesky Spravochnik, Khimia, Leningrad, Russia, 1991.

[16] M. Y. Gorbachev, "Influence of intra-molecular conformational transitions and some physico-chemical quantities of liquids on their thermal conductivity," Physics and Chemistry of Liquids, vol. 40, no. 4, pp. 395-403, 2002.

[17] V. G. Dashevsky, Conformacii Organicheskikh Molecul, Khimija, Moscow, Russia, 1974.
[18] B. S. Almeida and M. M. Telo da Gama, "Surface tension of simple mixtures: comparison between theory and experiment," Journal of Physical Chemistry, vol. 93, no. 10, pp. 4132-4138, 1989.

[19] C. A. Croxton, Liquid State Physics-A Statistical Mechanical Introduction, Cambridge University Press, Cambridge, UK, 1974.

[20] A. K. Saroha, "Safe handling of chlorine," Journal of Chemical Health and Safety, vol. 13, no. 2, pp. 5-11, 2006.

[21] N. B. Vargaftik, Spravochnik po teplophisicheskim svoistvam gazov i zhidkostei, Gosudarstvennoe Izdatelstvo Phiziko-Matematicheskoi Lietratury, Moscow, Russia, 1963.

[22] G. J. Janz, G. R. Lakshminaryanan, R. P. T. Tomkins, and J. Wong, "Molten Salts, v. 2 Section 2. Surface Tension Data," National Bureau of Standarts 28, Washington, DC, USA, 1969.

[23] I. L. Knunjanc, Ed., Khimicheskaja Enciklopedija. Tom 1, Sovetskaja Enciklopedija, Moscow, Russia, 1988.

[24] I. L. Knunjanc, Ed., Khimicheskaja Enciklopedija. Tom 3, Bolishaja Rossiiskaja Enciklopedija, Moscow, Russia, 1992.

[25] I. L. Knunjanc, Ed., Kratkaja Khimicheskaja Enciklopedija. Tom 4, Sovetskaja Enciklopedija, Moscow, Russia, 1965.

[26] I. T. Goronovsky, P. Yu. Nazarenko, and E. F. Nekrjach, Kratky Spravochnik Po Khimii, Naukova Dumka, Kiev, Ukraine, 1987.

[27] C. L. Yaw and W. Andrew, Thermophysical Properties of Chemicals and Hydrocarbons, Norwich, New York, NY, USA, 2008.

[28] S. G. Frankiss, "Vibrational spectra and structures of $\mathrm{S}_{2} \mathrm{Cl}_{2}$, $\mathrm{S}_{2} \mathrm{Br}_{2}, \mathrm{Se}_{2} \mathrm{Cl}_{2}$ and $\mathrm{Se}_{2} \mathrm{Br}_{2}$," Journal of Molecular Structure, vol. 2, no. 4, pp. 271-279, 1968.

[29] K. S. Birdi, Ed., Handbook of Surface and Colloid Chemistry, CRC Press, New York, NY, USA, 3rd edition, 2008.

[30] D. Ambrose, "Critical temperatures of some phenols and other organic compounds," Transactions of the Faraday Society, vol. 59, pp. 1988-1993, 1963. 

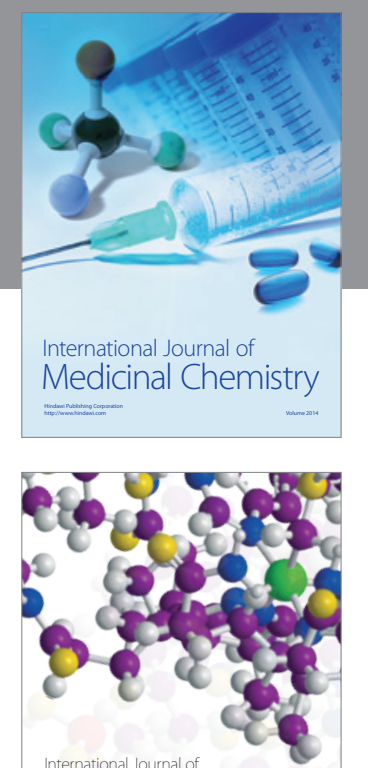

\section{Carbohydrate} Chemistry

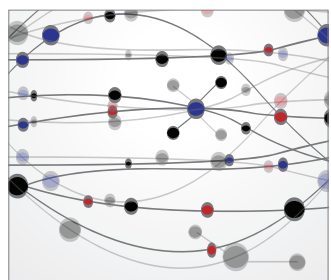

The Scientific World Journal
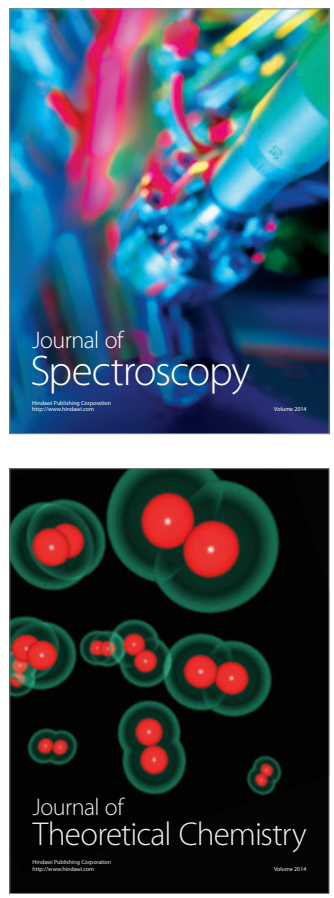
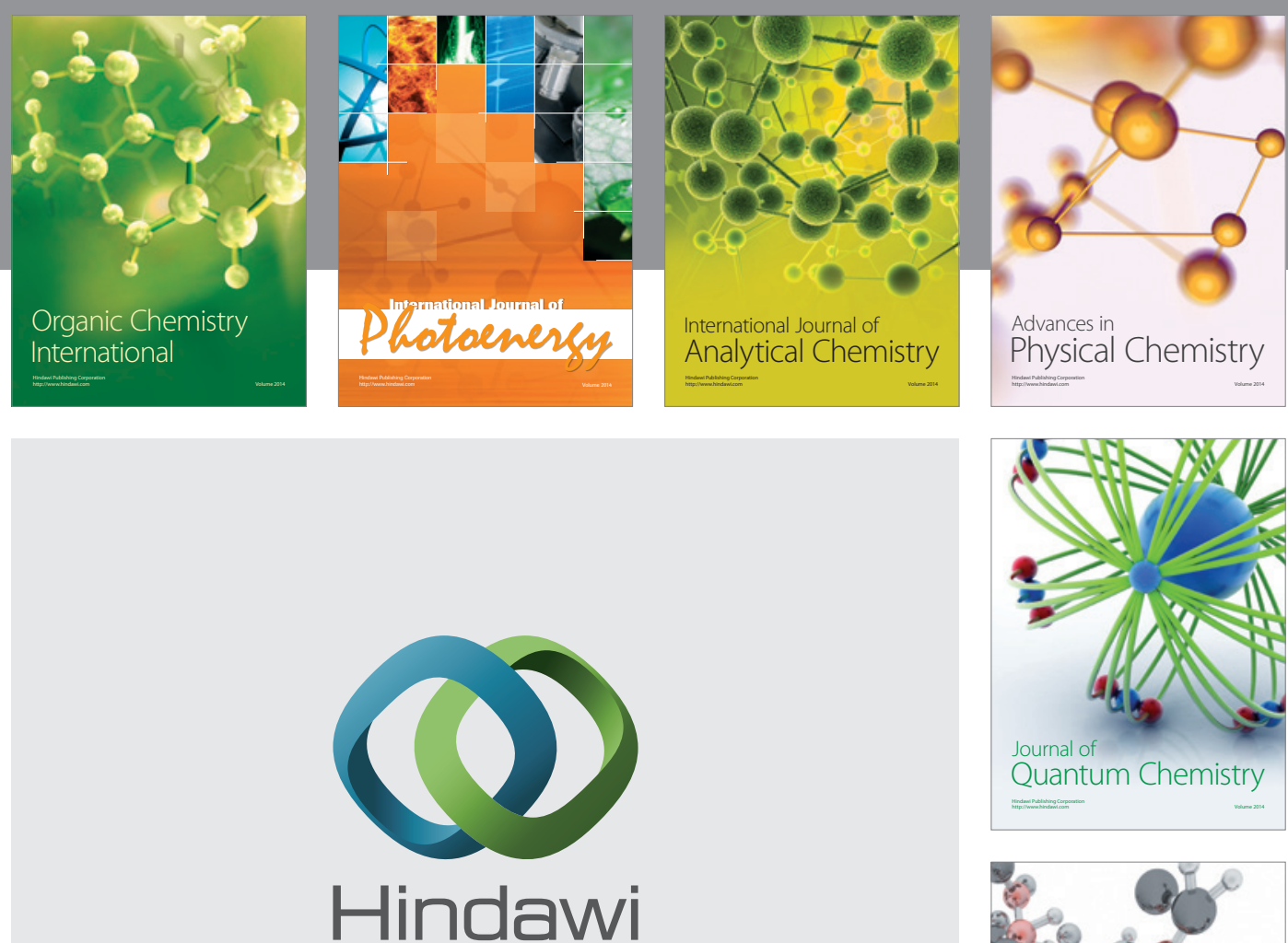

Submit your manuscripts at

http://www.hindawi.com

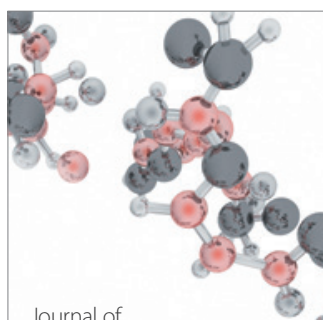

Analytical Methods

in Chemistry

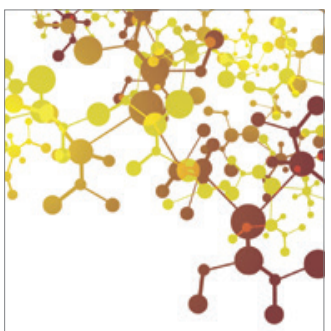

Journal of

Applied Chemistry

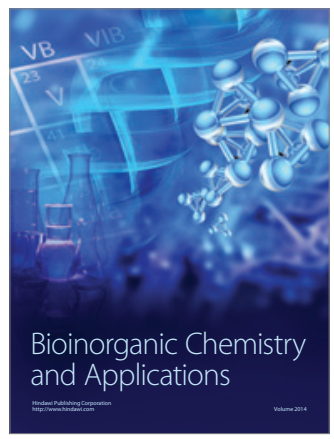

Inorganic Chemistry
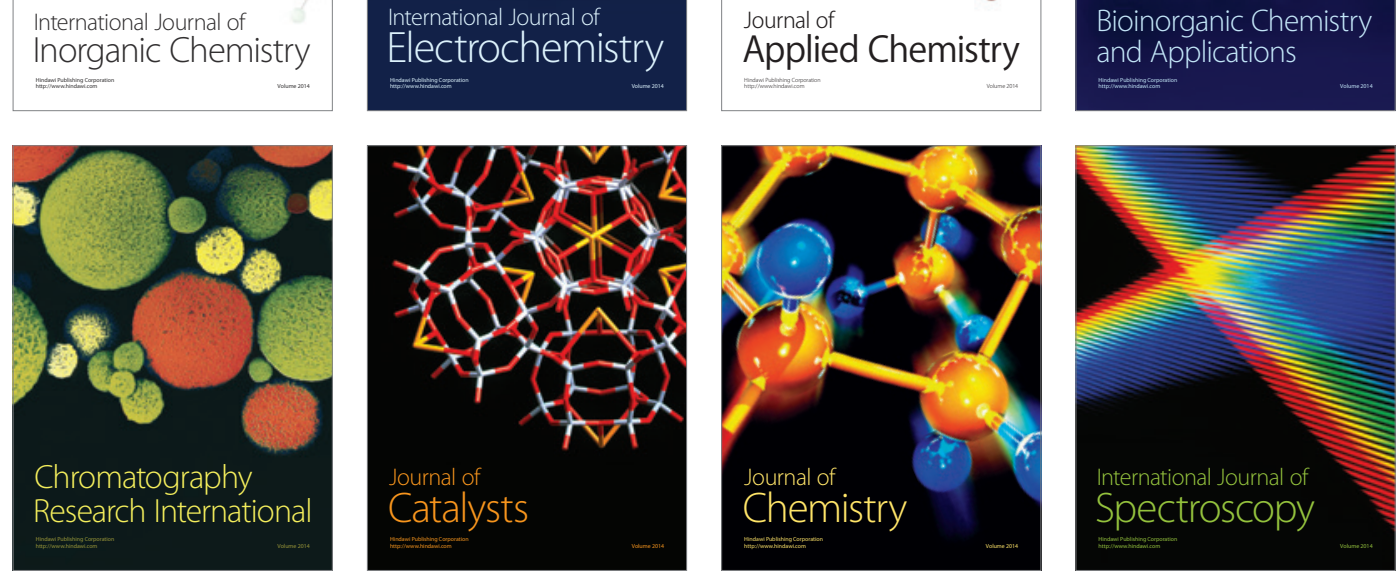